The Philosophical Journal of Conflict and Violence

Vol. II, Issue 2/2018

(C) The Authors 2018

Available online at http://trivent-publishing.eu/

\title{
Self-Care after Severe Injuries in Circus Artists: A Philosophical Inquiry
}

\author{
Bernard Andrieu, ${ }^{1}$ Josephine Buffet, ${ }^{2}$ Cyril Thomas, ${ }^{3}$ \\ Haruka Okui, ${ }^{4}$ Petrucia da Nobrega ${ }^{5}$ \\ ${ }^{1}$ EA3625 - TECStaps, Paris-Descartes University), France, bernard.andrieu@parisdescartes.fr \\ 2 EA3625 TEC-Staps, Paris-Descartes University, France. \\ 33CNAC -Chaire ICIMA, Chalons en Champagne, France, cyril.thomas@.cnac.fr \\ $4 \cdot$ Faculty of Social Studies, Doshisha University, Japan. \\ ${ }^{5}$ Estesia -Sport, UFR Norte Natal Brasil, Brazil, pnobrega@ufrnet.br
}

\begin{abstract}
This study is based on the self-reporting by circus artists' concerning their injuries. We refer to the theoretical framework of emersiology and argue that circus artists may be able to soothe their distress and pain by learning through their body. We will draw further on the comparison between our therapeutic approach and the techniques of self-care introduced by Michel Foucault in his History of Sexuality.
\end{abstract}

Keywords: Michel Foucault; Marcel Mauss; Circus Arts; Injury; Philosophy of Body; SelfCare.

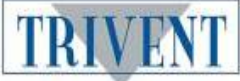

The PJCV Journal is published by Trivent Publishing.

This is an Open Access article distributed in accordance with the Creative Commons Attribution Non Commercial (CC-BY-NC-ND 4.0) license, which permits others to copy or share the article, provided original work is properly cited and that this is not done for commercial purposes. Users may not remix, transform, or build upon the material and may not distribute the modified material (http:/ / creativecommons.org/ licenses/by-nc/4.0/) 


\title{
Self-Care after Severe Injuries in Circus Artists: A Philosophical Inquiry
}

\author{
Bernard Andrieu, ${ }^{1}$ Josephine Buffet, ${ }^{2}$ Cyril Thomas, ${ }^{3}$ Haruka Okui, ${ }^{4}$ Petrucia da \\ Nobrega ${ }^{5}$ \\ ${ }^{1}$ EA3625 - TECStaps, Paris-Descartes University), France, bernard.andrieu@parisdescartes.fr \\ ${ }^{2}$ EA3625 TEC-Staps, Paris-Descartes University, France. \\ 3 CNAC -Chaire ICIMA, Chalons en Champagne, France, cyril.thomas@cnac.fr \\ $4 \cdot$ Faculty of Social Studies, Doshisha University, Japan. \\ ${ }^{5}$ Estesia -Sport, UFR Norte Natal Brasil, Brazil, pnobrega@ufrnet.br
}

\begin{abstract}
This study is based on the self-reporting by circus artists' concerning their injuries. We refer to the theoretical framework of emersiology and argue that circus artists may be able to soothe their distress and pain by learning through their body. We will draw further on the comparison between our therapeutic approach and the techniques of self-care introduced by Michel Foucault in his History of Sexuality.
\end{abstract}

Keywords: Michel Foucault; Marcel Mauss; Circus Arts; Injury; Philosophy of Body; SelfCare.

\section{Introduction}

We will first introduce the theoretical framework of our study. Then, we will briefly describe our experimental group as well as the methods used in this study.

Our study distinguishes between three levels of the human body. The first level corresponds to the body described through cognition, that is, described from an intellectual point of view with the help of our representations. For instance, someone may describe his injury by stating that his pilon fracture was caused by a motor vehicle accident. Regarding the body, this first perspective can almost be seen as an external one. The second level corresponds to the lived-body, that is, the body experienced through one's feelings and consciousness-e.g. the pilon fracture is more intimately experienced by the individual as a painful and traumatizing event. The third level corresponds to the living-body, that is, the body that has a life of its own which goes beyond consciousness. Regarding our example of the motor vehicle accident, it is worth noticing that multiple aspects of the formation of the pilon fracture cannot be immediately experienced or known through the cognitivedescriptive perspective or through the point of view of the lived-body. To summarize briefly: (1) the described-body is the body mediated by representations that allow us to interpret or analyze the situation (i.e., it more generally refers to what the individual is able to say about his own body); (2) the lived-body is the body mediated by our emotions; (3) the living body corresponds to the deepest level-multiple phenomena pertaining to the livingbody occur before we are aware of them.

The implicit activities of the living body (such as heart rate, involuntary gestures, stress, reflexes, emotional regulations etc.) emerge into our consciousness (i.e., the lived body) without the control of our will. In other words, the language of the living-body is mostly 
unconscious. One of our main hypotheses is that the information perceived by consciousness is produced by the living-body during its ecologization into the world. The whole set of data communicated by the body does not appear to consciousness (or the lived body) in a simultaneous and transparent way. Regarding the activity of the living body, the conscious response of the lived body differs in time.

Emersiology $^{1}$ refers to a distinctive set of methods and practices-called somatechnies-through which subjects can gain some access to the third level of the lived body. It is a theory that analyzes the emergence of non-visible data of the living-body. It further shows how these datum may (notwithstanding their unconscious nature) be taken into account by subjects.

Let us now turn to our experimental group. On May 18, 2016, during our teachings on the philosophy of body to circus artists, students attending the 29th anniversary Gala of the National Center of Circus Arts (Centre National des Arts du Cirque, Cnac) were asked to complete the following task: "Describe your body's experience (gestures, learning, exercises...), using the three following levels of interpretation: unconscious body, bodily techniques, and consciousness." More specifically, our experimental group was asked to analyze perceived infra-corporality by reporting specific sequences in their learning of the circus arts according to the following three levels of narrative: (1) sequences pertaining to the unconscious level of activity of the living body; (2) sequences pertaining to the techniques of the body resulting in habitus (in the sense of Marcel Mauss); (3) sequences pertaining to an entirely conscious activity. It is in this specific context that we started our philosophical inquiry into severe injuries. However, before presenting our study's findings, we need to consider some Foucauldian aspects regarding self-writing and the culture of the self.

\section{Self-Reports of Severe Injury}

To become an art of existence, good management of the body ought to include a setting down in writing carried out by the subject concerning himself; with the help of this notetaking, the individual would be able to gain his independence and choose judiciously between what was good and bad for $\operatorname{him} . .{ }^{2}$

\section{Michel Foucault}

Self-reporting or self-writing, the "telling of the self" from the Ancient Greek hupomnêmata, of one's health or sickness, or of one's injury as discussed here, can be established through correspondence, biographies or autobiographies. Self-writing pertains to the internal movements of the soul. More importantly, exercises in self-writing are, for the author and his readers, similar to "a training of the self by the self." ${ }^{3}$ In self-reporting, the most conspicuous purpose is to become able to think about one's health and comprehend one's state. Self-writing reflects the author's effort to modify his state by considering the reader's position (whether the reader is the author himself or someone else).

\footnotetext{
1 Bernard Andrieu, Jim Parry, Alessandro Porrovecchio, Olivier Sirost, Body Ecology and Immersive Leisure (London: Routledge, 2018).

2 Michel Foucault, History of Sexuality. Volume 2: The Use of Pleasure, trans. Robert Hurley (New York: Vintage Books, 1990), 108.

3 Michel Foucault, "L'écriture de soi," in Dits et écrits. Tome 4 (Paris : Gallimard, 1983), 417.
} 
Therefore, in self-reporting the body is sometimes reduced to a state of slavery by the power of reflection. Keeping track of one's food and beverage intake and physical activity is a means to observe oneself through a writing exercise. As noticed by Foucault:

There are the meditations, the readings, the notes that one takes on books or on the conversations one has heard, notes that one reads again later, the recollection of truths that one knows already but that need to be more fully adapted to one's own life. ${ }^{4}$

However, written thoughts on the suffering undergone by the body during physical activity enable the subject to distinguish the most intimate effects of the injury from its physical causes. In the culture of the self, emphatic awareness has a curing and therapeutic role. In contrast, metaphoric expressions such as "to cure, to amputate, scarification, purge" 5 are sometimes applied to reflections on body and soul in ancient Greek culture. In this context, violence appears as a technique of internal constraint; especially with stoicism, Greek morality already anticipates the rise of the violent rigourism aimed at taking control over each gesture of the human body. Taking power over one's body through an external set of obligations is an internal violence, that is, a violence that one inflicts upon oneself.

It is important to notice that self-reports or autobiographical writings are strongly related to therapeutic aims. Indeed, medicine is a practical knowledge (epistemê praktikê) and a tekhne which must adapt itself to specific cases. Based on "knowledge of what the body is in its own reality," "we see that the soul can only be cured through the body. Galen, for instance, is not a "technician of the soul." The art of diagnosing depends on the patient's specific case. It is through the self-management of Epictetus' "medical premises" (iatreon) that the patient will be empowered with respect to his condition. These medical premises were the crux for the health of body and soul. However, without the patient's awareness of his illness, medical treatment cannot be related to the culture of the self. It is important to notice that the sickness of the body cannot be separated from the state of the soul. Rather, Pathos must be conceived as a means to establish the culture of the self within oneself. For, as stated by Foucault, "The final objective of conversion to the self is to establish certain relations with oneself." 8

As shown by Foucault in Confessions of the Flesh, pastoral power in early Christianity inherited from the techniques of the body developed during Antiquity. ${ }^{9}$ However, contrary to Antiquity, Christianity turned those techniques into means of subjugating individuals' mind and body. In contrast to this Christian approach, we propound an analysis of the activity of the living body after a severe injury. Due to the difficulties of making a direct reflexive analysis on this subject matter, we asked members of our experimental group to write self-reports. In our research study, we asked our subjects to write an autobiographical account of their experience with severe injury by paying special attention to the consequences of their injury regarding the lived-body.

\section{Recollections of Severe Injury}

First of all, injury is the sudden interruption of the usual learning-process. Injury breaks

\footnotetext{
4 Michel Foucault, The History of Sexuality Volume 3. The Care of the Self, trans. Robert Hurley (New York: Pantheon Books, 1986), 51.

5 Michel Foucault, "L'herméneutique du sujet," in Dits et écrits, 357.

6 Michel Foucault, L'Herméneutique du Sujet (Paris : Gallimard, 2001), 323.

7 Ibid., 381.

8 Michel Foucault, The Hermeneutics of the Subject, trans. Graham Burchell (Basingstoke: Palgrave Macmillan, 2005), 495.

${ }^{9}$ Michel Foucault, Les Aveux de la chair (Paris : Gallimard, 2018).
} 
with the common process of mastering and assimilating techniques. Severe injury directly contradicts common representations of the self. Of course, through training and numerous efforts, circus artists become able to increase their resistance regarding pain. However, the pain experienced during severe injuries can be so strong that it no longer corresponds to the usual esthesiological scale. In some instances, the experience of injury goes beyond common representations of corporeal self-control.

In circus arts, over-training may result in injuries related to fatigue. However, sudden and severe injuries are different insofar as subjects are not mentally prepared to this kind of experience. Indeed, when someone experiences a sudden and severe injury, he is often unable to bring the memory of a past and similar trauma into his mind; the injury appears as an event which is radically new and unprecedented. Hence, the only way to assess one's suffering is to compare its intensity to other recollections of accidents and injuries. In a nutshell, the search in the body for the memories of sensory coordinates favors locating the other incorporated memories of trauma in order to evaluate the intensity of pain.

In addition, accidents and injuries in circus arts are not only about physical pain. Subjects often mention their moral suffering caused by the personal experience of technical and physical failure. Results of our study show that experiences of artistic failure become deeply rooted in body-related memories. We may even say that feelings of failure tend to leave a permanent trace in subjects' memories. Even after wounds are entirely healed, these feelings remain. Psychological trauma persists and goes far beyond the state of complete physical remission. This is further evidenced by the fact that subjects often mention their personal unease and anxieties when, during new trainings, they are about to follow the same behavioral sequences as those that led to their injury. One of our subjects, Ramos Hernandez Angel Paul mentioned his injury, which was beyond physical healing with the help of a formal-logical sequence of his accident: "Habits + Acquired (sic.) = Automatism = Accident = Injury."

Ramos Hernandez Angel Paul further recounts that his wound and the role his memory had in changing his state of consciousness at the time his trainings resumed:

Our bodies do not lie to us. The body informs us about our troubles, our conflicts, our sufferings. When we live an emotion in the present, there is always a resonance with a past emotion. Although the experience can be totally different, the emotion felt will be the same. There is always a trace, a memory that allows to recognize the emotion. The mind always acts in this way; it will initiate a process of recognition through memory and comparison. In its roots, the body will (or will not) find a way to inform us about a similar experience and to reactivate emotions related to that experience."

Hence, although severe injuries involve physical and psychological trauma, we notice that the latter eventually takes precedence with feelings of fear, loss of self-confidence, and mental blocking. This psychic dimension of the experience of severe injury appears in the vocabulary used by our experimental group-i.e. in order to explain their personal issues, subjects often refer to words such as "obsession," "frustration" and "exhaustion."

\section{The Assimilation of Trauma}

Circus artist Inbal Ben Haim practices aerial rope. As a subject of our experiment, she wrote a text entitled "Whole body, broken body," in which she describes her experience with severe injury. According to her, three factors caused her accident: (1) fatigue and lack of preparation during the conception of the circus performance; (2) sickness during the week of the accident; (3) insufficient warm-up exercises before walking on the rope. She 
acknowledges that various signals transmitted by her living body already made her foresee that she would not succeed in her performance. However, she states that, regarding her accident, several issues in her household and as well psychological stress regarding the conception of her performance also played a significant role. During her accident, Inbal Ben Haim recalls that the tearing sound and the strange sensation of pain in her shoulder area did not enable her to immediately understand that she hurt herself.

For a while the injury prevented her from practicing aerial rope. However, the injury also prompted a new awareness regarding the use of her body. She observed that the techniques of the body must be adapted to a "reflexive learning", leading to a new way to work with one's body. Inbal Ben Haim had to learn how to use her legs, hocks, toes, pelvis and left shoulder differently than prior to her accident. She states that somatic practice, sophrology and body-mind centering exercises favored her immersion into her own sensations and helped her to gain a new awareness regarding her physical and mental state.

As well, rediscovering the fun of practicing aerial rope appears to be a crucial part of Ben Haim's personal experience of getting over her injury. After her surgery, the circus artist mentioned a feeling of "total weakness". However, as evidenced by the "attention paid to... nutrition, physical exercises, sleep," her degree of awareness regarding her own body clearly increased. The subject recomposed her internal body-patterns through learning new "habits and reflexes aiming to protect the area of [physical] trauma." The past experience of great pain tended to accentuate the body-mind dissociation in the subject. The difference between the subject's usual sensations and the (unprecedented and unexpected) sensations resulting from severe injury implied a reorganization of the esthesiological scale in order to reconstruct a sense of emotional wholeness.

Ben Haim recovered after seven months of rehabilitation. She lays emphasis on the pivotal role of her consciousness regarding "decisions of voluntary actions that are strange to my body after such a long break." Various tests and exercises become necessary in order to gradually become able to perform gestures that were far more spontaneous prior to the accident. The subject's mental preparation significantly increased. She noticed a gap between her representations of her own body and her "[actual] body. I feel that my shoulder is like disconnected from the rest of my body." In other words, representations of a weak and incapable body are experienced as a serious impediment.

Ben Haim's remarks obviously pertain to the gap between the lived-body and the livingbody. She mentions "a gap between the representation of [her] body" prior to the accident and representations of her body's capacities, of the exercises and gestures she was able to do, after her injury. A therapy aimed to rebuild links between the living body, the mental image of the body and internal sensations is still ongoing. Contrary to other forms of therapies whose sole aim is to reorganize the life and body of the patient around its consciousness, incorporeality refers to the therapeutic method that aims to improve the patient's awareness regarding the relations between the three levels of his body (i.e., described-body, lived-body, and living-body). We shall now address the question of overcoming protective reflexes after the experience of severe injury. Indeed, those reflexes may prevent circus artists to perform techniques and gestures that were perceived as spontaneous and normal prior to accident.

\section{Protective Action of the Body}

Reflexes are spontaneous and protective movements that the human body uses against possible harm and threats in its environment. Without the action of free will, the corporeal reaction leads to a regulation of the organism which reshapes matter and form within the limits of body-plasticity. Given that the actions of the living body go beyond our will and consciousness, we must ask; how can someone reduce the level of reflex movements in 
order to regain his ability to perform gestures and techniques that, prior to the accident, were part of the body's normal habits and patterns? Despite of the largely unconscious nature of living-body phenomena, could there be a way for the subject to increase his motor capacities?

Let us turn to the statement of another of our subjects. Steve Bernard talks about his thoughts and emotions regarding his practice of trampoline as follows:

The first time, I feel a deeply anchored malaise related to the unknown [consequences of the trampoline jump]. First, I must overcome this malaise and pay attention to what my body is telling me. I know that the malaise can manifest itself in an innate reflex that could be dangerous to me, for example "refusal" in the middle the performance. The first times when I practiced trampoline, I frequently had the feeling that my body was saying "no." It is as if my body, impressed by my actions, suddenly stops giving relevant indications. This leads to the sensation that the body is "cut-off." I have the feeling to enter a black hole in which one "loses oneself.

Steve's description relates to the protective action of the body which is determined by his brain to trigger a response. He further distinguishes this awareness or high level of attention (resulting from neuronal activation) from the mere attitude of "being focused." Concentration pertains to a "more delineated and specific space" than the high level of attention that Steve refers to.

This attention can create "new forms of apprehension." The circus artist Antonin Bailles expands on the role of the unconscious, which can prove to be both positive and negative by forbidding changes of behavior or attitude: "The unconscious is predominant during this phase [of the performance]. In addition, the use of body techniques is often unconscious as well. If [during the performance] consciousness was too present, fear would change behaviors and gestures in a harmful way." Especially the loss of visual cues often leads to innate protective reflexes that cut off the desired acrobatic gesture. Hence, a regular practice of acrobatics on the ground or on the trampoline is necessary in order to remain attentive to the datum of the living-body and to counteract the effects of unconscious reflexes of protection.

Eventually, minimizing reflexes is based on the acceptance and understanding of the logic of the living-body, a logic that often goes beyond our conscious representations. As stated by one of our subjects: "We must find a way to unlock our innate protective reflexes. We must go beyond fear and further psychological impediments. Then, thanks to a (conscious) concentration on specific and controllable elements, we must relearn the appropriate technique that will fit durably into our [corporeal] habitus." Let us now turn to more theoretical and philosophical considerations regarding somatechny and self-care.

\section{Somatechny or Self-Care after Trauma}

The aim of Andrieu's studies on health and the self is to explain how subjects gradually integrate cultural and social body techniques as part of their physical education. ${ }^{10}$ Somatechny is a technique through which subjects may gain access to the deeper level of their living-body. In the light of this, it is worth noticing that some body-techniques can be defined as a form of somatechny based on the sense of touch. Nowadays, body awareness activities or massage techniques are commonplace. These techniques offer subjects new

10 Bernard Andrieu, "From Phenomenology to Emersiology: The birth of living body in the philosophical research in France among 1990", Study on Arts and Principles of Body-Mind Transformation 4 (2015). 
corporeal experiences. Once subjects internalize these techniques, new feelings and sensations arise regarding their interaction with their environment; they get a new sense of how their body interacts with the world.

Marcel Mauss was the first to address the topic of body techniques which he defined as "the way in which from society to society men know how to use their bodies." 11 Mauss' notion of "body techniques" and Andrieu's concept of somatechny are similar inasmuch as both are based on the contention that techniques are effectively internalized by the human body. However, contrary to Andrieu, Mauss thinks that a subject cannot self-define his own body-especially if this subjective definition is not compatible with social norms. According to Marcel Mauss, body techniques especially express subjects' internalization of cultural norms. While Mauss' "body techniques" are unconsciously internalized, Andrieu's notion of stomatechny refers to a conscious use of body techniques with a view to transforming the self. Somatechny is a means to improve knowledge of one's body through awareness and attention. According to Andrieu, learning through one's body ${ }^{12}$ amounts to the assessment and identification of the effects of body's techniques inside the human body.

Through our case studies, we can see that somatechnies appear as a set of tools helping circus artists to become the subjects of their own trauma. In other words, somatechnies ensure the subjectivation of the actual matter and form of one's injury. New ways to use one's body and to relate to it help promote a new definition of the self. It is by means of subjectivation of their injury-based on the awareness of the lived-body and living-body that circus artists comes to believe in the possibility of a personal revolution. However, it is important to notice that these new ways to use one's body and to relate to it are not necessarily emancipatory techniques. Techniques of self-control of the body can indeed be part of bio-power techniques which, in Foucault's words, aim to achieve the "subjugation of bodies and the control of populations." 13 By working on their own bodies, individuals may be subjected to forms of surveillance and domination that are reminiscent of panopticism. Through the internalization of bio-power related techniques, patients become agents ensuring their own health. In any case, there are conspicuous analogies between bio-power techniques and sports. Body coaches, for instance, want their students to learn and internalize a set of techniques for the sake of their health and well-being. Triathlon contestants assimilate techniques and acquire a new way to relate to their bodies; they aim to build themselves a new "self" that will be able to handle the pain entailed by their efforts. ${ }^{14}$

In contrast to the techniques of subjugation of bio-power, our study lays emphasis on the virtues of self-care (which relies on subjects' autonomy). Self-care is an ancient medical procedure which is fruitful in its own right. Through self-care, the individual seeks to become the subject of his own evaluation, medication and cure. Resisting to the exogenous diagnosis of the practitioner, the subject aims to soothe his distress and pain through his own personal experience. Through the assimilation of new techniques, the subject learns to relate to his body in a different way. Then, his body no longer appears as an obstacle to the cure. On the contrary, the subject's personal knowledge and experience of his body will play an active role regarding the diagnosis, therapeutic protocol, and positive psychophysiological effects of medical treatment. This regulation of pain and distress by

\footnotetext{
${ }^{11}$ Marcel Mauss, Sociology and Psychology: Essays (London: Routledge and Keegan Paul, 1979), 97.

12 Bernard Andrieu, Learning through his body (Rouen: P.U. de Rouen/Le Havre, 2019).

13 Michel Foucault, The History of Sexuality. Volume I, trans. Robert Hurley (New York: Pantheon Books, 1978), 140.

${ }^{14}$ See for instance Olivier Bessy, The North Face Ultra Trail du Mont-Blanc (Grenoble: Ed le Petit Montagnard, 2012).
} 
self-care becomes a technique of self-help. To conclude this paper, we would like to draw a comparison between our study on circus artists and Foucault's thoughts on self-care.

\section{Some Reflections on Self-Care and Michel Foucault}

In his last writings, especially, Foucault studied the ways in which subjects strive to find the truth about themselves. Foucault showed that self-expertise and self-diagnosis entail a relation between the subject and truth about itself which puts into question the status of doctors as exclusive owners of health knowledge. Subjects must be aware of their bodily state, especially given that illness (except when subjects cannot be aware of their own condition) "can in general be detected through pulse, bile, temperature, pain." 15 Subjects' mastering of the medical $\log o$ is a means to assess their health independently. If the medical logos is both regarded as a broad framework of knowledge and a set of guidelines, then one can use this logos in order to reach a deep and healthy intellectual relationship with oneself. Consequently, medical knowledge and practice can, at least partially, develop without the direct intervention of doctors.

This leads us to the general and ethical notion of self-control. As illustrated by the "relationship between the body and health issues,"16 self-control strives to discover and create ethical guidelines in the most practical way (i.e., through trials and errors that are assessed by the subject itself). In The Use of Pleasure, Foucault studies Ancient Greek conceptions of the body based on the notion of energy. In this regard, he introduces what he sees as the "privileged domain for the ethical formation of the subject." The ethics of self-control refer to

.... a subject who ought to be distinguished by his ability to subdue the tumultuous forces that were loosed within him, to stay in control of his store of energy, and to make his life into an oeuvre that would endure beyond his own ephemeral existence. The physical regimen of pleasures and the economy it required were part of a whole art of the self. ${ }^{17}$

Managing self-control through a tekne of the body amounts to know how to not push oneself too hard, to restrain oneself, to maintain a diet, etc. The subject must regard prescriptions and practice an ascetism aiming at the ideal of "absolute purity." 18 Regarding the relationship to oneself, health is, along with the behavior towards spouse and children, one of three pillars of "austerity." 19

Foucault states that self-mastering or control over oneself is comparable to the control of a king over his kingdom. In ascetism, renunciation of any kind of sexual intercourse represents a high-level of self-control. Passions of the flesh are completely restrained. Wet dreams are only a residual waste of energy in which the subject does not play an active role. ${ }^{20}$ In this process of purification, it is less the ideal of renunciation that prevails than the aim to reshape the meaning of the biological phenomena occurring in one's body.

Asceticism is a technique of self-reflection. It is a practical process of self-questioning through which the subject puts itself in a position where he can and must think about his own situation. By questioning his own lifestyle, the subject may become able to separate what is dangerous or harmful for the oneness of his own self from what contributes to a fruitful life. Practical and intellectual efforts towards self-sufficiency can be defined as a kind

15 Michel Foucault, L'usage des plaisirs (Paris: Gallimard, 1984), 74.

16 Michel Foucault, "Le souci de la vérité," in Dits et Ecrits, 673.

${ }_{17}$ Michel Foucault, History of Sexuality. Volume 2: The Use of Pleasure,139.

18 Michel Foucault, "A propos de la généalogie de l'éthique : un aperçu du travail en cours," in Dits et Ecrits (Paris: Gallimard, 1984), t. 4, 620.

19 Ibid., 621.

20 See Michel Foucault, "Le combat de la chasteté," in Dits et Ecrits, 305. 
of somatechny, that is, as a means to learn through one's own body. Foucault's study of dietetics will help us to illustrate the similarities between Ancient Greek practices of selfcare and somatechny. It is worth noticing that dietetics are not an end in itself. As shown by Foucault, Dietetics neither amount to blind obedience of rules, nor do they amount to achieving absolute control over one's body. Rather, dietetics are a lifestyle based on knowledge and reflection about the forms, choices, and variables pertaining to a "concern with the body." ${ }^{21}$ Dietetics do not consist in a set of rules that are set in stone. The diet gives the subject the opportunity to reflect on a qualitative change in his or her life and to measure its effects. As stated by Foucault:

Regimen should not be understood as a corpus of universal and uniform rules; it was more in the nature of a manual for reacting to situations in which one might find oneself, a treatise for adjusting one's behavior to fit the circumstances. ${ }^{22}$

While the Greeks tried to become familiar with the findings of physics, cosmology, and dietetics, their aim was to reach self-sufficiency. In Ancient Greek thought, matters of personal health and ecological thinking go hand in hand. Subjects work to maintain a balanced state of body and mind by considering both themselves and their environment. In this respect, Ancient Greek thought laid emphasis on the importance of the opportune moment or Kairos. The kairos defines the perfect balance between what is needed and when it is needed. Body and soul must find the most importune moment to act. Techniques of self-care therefore always involve proportionate and processed choices. As observed by Foucault, self-care is constantly related to an ecological way of thinking:

The practice of regimen also implied a "circumstantial" vigilance, a sharply focused yet wide-ranging attention that must be directed toward the external world, its elements, its sensations: the climate of course, the seasons, the hours of the day, the degree of humidity and dryness, of heat or cold, the winds, the characteristic features of a region, the layout of a city. And the relatively detailed instructions that are given by the Hippocratic regimen were meant to help the individual who familiarized himself with them to modulate his way of living according to all these variables. ${ }^{23}$

\section{Conclusion}

According to Foucault, the main features of self-care are: (1) awareness to one's mind and body; (2) self-questioning; (3) attention paid to the environment and Kairos; (4) autonomy and transformation of the self. The same features of self-care apply to our case studies on circus artists. Circus artists first have to become aware of the effects caused by the accident on their mind and body. In other words, they had to notice with precision the persistent impact of trauma (physical and psychological) on their life. Through a process of selfquestioning during their trainings, circus artists became able to identify the specific issues that they need to overcome (such as the mind-body dissociation, the impediments due to protective reflexes, or the loss of confidence in the usual training processes). Then, circus artists tried to find appropriate exercises in order to regain an acute sense of their environment. They also paid attention to the opportune moment-especially in order to "unlock" their "protective reflexes" to become able again to perform the same acrobatic gestures as prior to the accident. Moreover, subjects in our group did not relate to their

\footnotetext{
21 Michel Foucault, History of Sexuality. Volume 2: The Use of Pleasure, 106.

22 Ibid., 106.

${ }^{23}$ Ibid., 106.
} 
trauma in a passive way. Rather, as we previously mentioned, circus artists learned through their body how to become the subjects of their trauma. They did not merely deny the existence of trauma but strived to "integrate it as fully as possible into the management of health and the life of the body." 24 Thereby, circus artists discovered new ways to use their body and to relate to it-which leads to a qualitative change of the artist's self. Eventually, a better sense of autonomy is achieved given that our subjects gradually became able to regain confidence in their acrobatic capacities by themselves, that is, by learning through their body. They became more and more able to assess and improve their health independently. In the end, each subject was at the same a patient and his own therapist or physician. Let us recall that, in Xenophon's Memorabilia, Socrates defines self-care as follows:

He also vehemently turned his companions toward attending to their health by learning from those who know how, as much as was possible, and by each one turning his mind to himself through his whole life, that is, to which food or which drink or what sort of labor was to his advantage and how he might live most healthfully by making use of these things. For he said that someone who turned his mind toward himself in this way would have to work to find a doctor who discerned better than himself what was advantageous for his health. ${ }^{25}$

\section{References}

Andrieu, Bernard. Learning Through his Body. Rouen: P.U. Rouen, 2019.

. "From Phenomenology to Emersiology: The birth of living body in the

philosophical research in France among 1990. » Study on Arts and Principles of Body-Mind Transformation 4 (2015).

Andrieu, Bernard, Parry, Jim, Porrovechio, Alessandro, Sirost, Olivier. Body Ecology and Emersive Leisure. London: Routledge, 2018.

Bessy, Olivier. The North Face Ultra Trail du Mont-Blanc. Grenoble : Ed le Petit Montagnard, 2012.

Foucault, Michel. Les Aveux de la Chair. Paris: Gallimard, 2018.

The Hermeneutics of the Subject. Translated by Graham Burchell. Basingstoke: Palgrave

Macmillan, 2005.

. L'Herméneutique du Sujet. Paris : Gallimard/Seuil, 2001.

. History of Sexuality. Volume 2: The Use of Pleasure. Translated by Robert Hurley. New

York: Vintage Books, 1990.

The History of Sexuality Volume 3. The Care of the Self. Translated by Robert Hurley.

New York: Pantheon Books, 1986.

L'Usage des Plaisirs. Paris : Gallimard, 1984.

Dits et Ecrits, t. 4. Paris : Gallimard, 1983.

The History of Sexuality. Volume I. Translated by Robert Hurley. New York: Pantheon Books, 1978.

Mauss, Marcel. Sociology and Psychology: Essays. London: Routledge and Keegan Paul, 1979.

Xenophon. Memorabilia. Translated by Amy L. Bonnette. Ithaca: Cornell Univers.

${ }^{24}$ Ibid., 98.

${ }^{25}$ Xenophon, Memorabilia, trans. Amy L. Bonnette (Ithaca : Cornell University Press, 1994), 146-147. 